ORI GI NAL

\title{
ASOCIACIÓN SEROLÓGICA DE LA RINONEUMONITIS VIRAL EQUINA Y LA ANEMIA INFECCIOSA EQUINA
}

\author{
SEROLOGI CAL ASSOCIATI ON BETWEEN EQUINE \\ RI NONEUMONITIS AND EQUI NE I NFECTIOUS ANEMI A VIRUSES
}

\author{
Julián Ruiz-Saenz, ${ }^{1}$ M.Sc, Ángel Cruz, ${ }^{2}$ MVZ, Érica Reyes, ${ }^{2}$ MVZ, \\ Albeiro López-Herrera, ${ }^{3}$ Dr. Sci, Agustín Góngora O, ${ }^{4 *}$ Ph.D.
}

\begin{abstract}
${ }^{1}$ Grupo de Investigación en Microbiología y Epidemiología, Universidad Nacional de CoIombia, Sede Bogotá, Colombia. Grupo de Inmunovirología, Universidad de Antioquia, Medellin, Colombia. ${ }^{2}$ Ejercicio Particular. ${ }^{3}$ Grupo BIOGEM, Universidad Nacional de Colombia, Sede Medellín. ${ }^{4}$ Grupo de Investigación en Reproducción y Genética Animal GIRGA, Escuela de MVZ, Universidad de los Llanos, Villavicencio, Colombia. * Correspondencia: agongora@unillanos.edu.co
\end{abstract}

Recibido: Agosto 31 de 2007; Aceptado: Febrero 20 de 2008

\section{RESUMEN}

Objetivo. Determinar el nivel de asociación serológica entre los herpesvirus equinos tipos 1 y 4 (HVE- 1 y HVE-4) causantes de la rinoneumonitis equina y el virus de la anemia infecciosa equina (VAIE) en caballos de trabajo provenientes de 5 municipios del Meta. Materiales y métodos. Se realizó una encuesta serológica transversal en 68 equinos provenientes de los municipios de San Martín, Guamal, Restrepo, Cumaral y Paratebueno. Para la evaluación de los anticuerpos contra los HVE-1 y HVE-4, se utilizó un ELISA indirecto para detectar la presencia de anticuerpos dirigidos contra la glicoproteína G del HVE- 1 y HVE-4 (Svanovir ${ }^{\text {TM }}$ EHV1/EHV4-Ab ELISA); para el diagnóstico de anticuerpos contra el VAIE se utilizó la prueba de inmunodifusión en agar de gel de Coggins. Resultados. No se encontraron reactores al HVE-1; sin embargo, el porcentaje de seropositividad fue de $94.12 \%(64 / 68)$ y $13.2 \%(9 / 68)$ para HVE-4 y VAIE respectivamente. El porcentaje de animales coinfectados HVE-4 y AIE fue $13.23 \%$ (9/68). Cuando se discriminaron los resultados por Municipio se encontró un $27.9 \%$ (19/68) de reactividad en el municipio de Restrepo, $26.5 \%$ (18/68) en Cumaral, $14.7 \%$ (10/68) en Paratebueno, 14.7\% (10/68) en Guamal, y 10.3\% (7/68) en San Martin. El porcentaje de reactores por municipio al VAIE fue Cumaral 5.88\% (4/68), Restrepo 4.4\% (3/68), Guamal 1.47\% (1/68) y San Martín 1.47\% (1/68). Conclusión. El alto porcentaje de coinfección entre HVE-4 y VAIE sugiere un efecto importante en la interacción, pues el efecto inmunosupresor del VAIE podría facilitar la reactivación del estado latente del HVE-4.

Palabras clave: Herpes, anemia infecciosa, virus, equinos. 


\section{ABSTRACT}

Objective. To determine the level of serological association between equine herpes virus 1 and 4 (EHV- 1 and EHV-4) and equine infectious anemia virus (EIAV) in horses from five municipalities of Meta department (Colombia). Materials and methods. A seroepidemiological survey was performed on 68 equines from the municipalities of San Martín, Guamal, Restrepo, Cumaral and Paratebueno. To evaluate antibodies against HVE-1 and HVE-4, specific indirect ELISA was used to detect the presence of antibodies directed against the glycoprotein G of HVE- 1 and HVE-4 (Svanovir ${ }^{\mathrm{TM}}$ EHV1/EHV4-Ab ELISA); to detect antibodies against VAIE the agar gel immunodifusion of Coggins was used. Results. There was no reactivity to HVE-1; however, the percentage seropositive was of $94.12 \%(64 / 68)$ and $13.2 \%(9 / 68)$ for EHV-4 and EIAV respectively. The percentage of CO-infected HVE-4 and EIA was $13.23 \%$ (9/68). When results were broken down by municipality, $27.9 \%(19 / 68)$ of reactivity was in the municipality of Restrepo, 26.5\% (18/68) in Cumaral, 14.7\% (10/68) in Paratebueno, $14.7 \%(10 / 68)$ in Guamal, and $10.3 \%(7 / 68)$ in San Martin. The percentage of reactors to EIAV by municipality was Cumaral 5.88\% (4/68), Restrepo $4.4 \%$ (3/68), Guamal $1.47 \%$ $(1 / 68)$ and San Martin $1.47 \%$ (1/68). Conclusion. The high percentage of co-infection between EHV-4 and EIAV suggests an important interaction effect, because the immunosupressor effect of EI AV could facilitate reactivation of the latent state of EHV-4.

Key words. Herpes, infectious anemia, virus, equines.

\section{NTRODUCCIÓN}

La rinoneumonitis viral equina es una enfermedad infecciosa de amplia diseminación, reconocida mundialmente y causada por los herpesvirus equinos tipos 1 y 4 (HVE-1 y HVE-4) (1). Aquellos países en los que se ha detectado la circulación de los virus, reportan altas pérdidas económicas causadas por problemas respiratorios, neurológicos, abortos y muerte en potros neonatos (1). La Anemia infecciosa equina (AIE), es una enfermedad de origen viral causada por un retrovirus con capacidad de infectar a cualquier équido y causar una enfermedad crónica sin tratamiento efectivo, la cual generalmente termina con la muerte o sacrificio de los animales (2).

LOS HVE- 1 y HVE- 4 son virus miembros de la subfamilia Alfaherpesvirinae; su genoma está constituido por una molécula de ADN de cadena doble entremezclada (dsADN), posee 150.2 y $145.6 \mathrm{~Kb}$ respectivamente $(3,4)$ y la diferencia entre los dos virus se determinó mediante enzimas de restricción $(5,6)$. La partícula madura consta de una nucleocápside que contiene el genoma viral y las proteínas asociadas (core). EI tegumento que rodea la nucleocápside y la envoltura viral la cual es derivada de la membrana celular del hospedero y tiene incorporadas las glicoproteínas de membrana codificadas por el virus (7).

EI HVE-1 fue aislado por primera vez de tejidos de fetos abortados en EEUU en 1933 (8); pero con base en estudios retrospectivos, ha sido reportado como causa de aborto desde 1921 en Australia (9). La infección por HVE-1 en particular, puede progresar a través de la mucosa respiratoria, dispersarse a otros sistemas orgánicos y causar aborto en el último trimestre de la gestación (5). Los fetos infectados con HVE-1 durante la gestación tardía pueden llegar a nacer vivos y a término, pero enferman al nacimiento o uno a dos días después del parto. Se caracterizan por su debilidad, son letárgicos, febriles, linfopénicos, presentan hipoxia y problemas respiratorios severos, con un deterioro clínico rápido y un pronóstico grave. En brotes epidémicos, la infección puede llevar a la 
presentación de mieloencefalitis, la cual puede variar desde una ataxia acompañada de incontinencia urinaria y fecal, hasta paraplejia o cuadriplejia con subsiguiente muerte del animal $(10,11)$.

Las infección por HVE-4, se ha asociado con la presentación de enfermedad respiratoria, la cual compromete el tracto respiratorio superior; además puede causar aborto y en raras ocasiones mieloencefalitis (6). La enfermedad respiratoria se presenta principalmente en potros en el período comprendido entre el destete y los 2-3 años de edad. Se caracteriza por que los animales presentan signos clínicos como fiebre, letargia, anorexia, linfadenopatía submandibular y descarga nasal profusa, la cual puede llegar a ser mucopurulenta como resultado de una infección bacteriana secundaria, causada principalmente por Streptococcus zooepidemicus. El virus puede alojarse en los pulmones y provocar una bronconeumonía exacerbada por infecciones bacterianas secundarias, con signos de enfermedad respiratoria del tracto bajo, como tos, sonidos anormales a la auscultación e incremento en el esfuerzo inspiratorio, entre otros $(6,12)$.

Cerca del $80 \%$ de las infecciones primarias por HVE-1 y HVE-4, son seguidas por un estado de infección viral latente en el ganglio trigémino; estado en el cual los caballos se encuentran fisiológicamente sanos (13). Sin embargo, luego de una situación de estrés (transporte, cambio de medio, preñez etc.), o una inmunosupresión, puede ocurrir una reactivación viral. Esta, conduce a una liberación de partículas virales a través de secreciones nasales y transmisión a otros caballos sanos susceptibles (6), estableciendo así un nuevo ciclo de infección (14). Esto significa que los reservorios epizootiológicos para HVE-1 y HVE-4, son los mismos caballos infectados en estado de latencia, los cuales son portadores y diseminadores intermitentes del virus, pudiendo llegar a comprometer la mayoría de la población equina de un criadero (14).

La AIE fue reportada por primera vez en 1843 por el francés Lignée, como una enfermedad de la sangre conocida con el nombre de "anemia hidrohémica o caquexia acuosa del caballo" (15). Años más tarde, en 1904, Vallée y Carré reportan la naturaleza infecciosa del agente filtrable implicado en la enfermedad (16). Su primer reporte en el nuevo continente fue en 1888 en Estados Unidos y hoy en día se encuentra distribuida por todo el continente Americano (17).

La AIE es históricamente importante porque fue la primera enfermedad equina en la cual se comprobó que es causada por un "agente filtrable" y que podía sobrevivir y mantenerse infeccioso aún pasándolo a través de filtros de porcelana (16); similarmente, la AIE fue la primera enfermedad causada por un retrovirus en la cual se ha logrado comprobar que el agente viral es transmitido por insectos vectores (18).

El virus de la AIE (VAIE) es un miembro del género Lentivirus perteneciente a la familia Retroviridae, posee un genoma ARN de doble cadena de $8.2 \mathrm{~kb}$ aproximadamente. EI VAIE tiene una distribución mundial y causa una infección persistente, caracterizada por episodios de fiebre recurrente, fiebre, trombocitopenia y pérdida de peso progresiva. Entre los Lentivirus, el virus de la anemia infecciosa equina es el único que presenta una rápida replicación viral y variación antigénica (19).

EI VAIE es el único de los Lentivirus, en el cual el curso clínico inicial de la infección resulta en una serie de ciclos claros, rápidos y dinámicos de enfermedad, asociados a la viremia durante las 3 primeras semanas posinfección, presentándose episodios recurrentes de enfermedad a intervalos irregulares separados entre semanas o meses uno del otro (19). Cuando los caballos son expuestos al virus de la AIE, estos pueden exhibir síntomas severos, agudos, de la enfermedad y pueden morir en 2 o 3 semanas. Esta forma de la enfermedad es la más dañina y es la más difícil de diagnosticar porque los síntomas aparecen rápidamente, y a menudo se nota solamente una elevada temperatura corporal. Los síntomas clínicos de la forma aguda de la AIE tienden a no ser específicos, y en los casos leves, la fiebre inicial puede ser de corta duración (frecuentemente de menos de 24 horas). Como resultado, cuando 
un caballo se infecta con el virus del AIE, puede que los propietarios y los veterinarios no se den cuenta de este síntoma inicial.

Los caballos infectados a menudo se recuperan y continúan moviéndose libremente en la población, tornándose en portadores crónicos de la infección. En este estado, los ciclos de la enfermedad duran entre 3-5 días y se caracterizan por fiebre, diarrea, letargia, edema, anemia y trombocitopenia. Este estado de enfermedad se ha definido como forma crónica de AIE, la cual típicamente ocurre entre los 8-12 meses posinfección. Posteriormente la frecuencia y severidad de los signos clínicos se van reduciendo en el tiempo. La enfermedad sufre un periodo de transición durante el primer año posinfección la cual va desde una forma crónica a una etapa inaparente de infección durante la cual los síntomas clínicos están ausentes y la viremia usualmente es indetectable o nula. Esta forma puede acompañar al animal hasta 20 años, el caballo afectado con la AIE crónica es el clásico "habitante del pantano", ha perdido su salud, se presenta letárgico, anoréxico, con un hematocrito bajo, y una persistente rebaja en el conteo plaquetario, especialmente coincidiendo con la fiebre causada por el virus de la AIE (20).

Los principales vectores mecánicos de la infección son los tábanos del orden Diptera representados por el género Stomoxys calcitrans o mosca del establo, los cuales adquieren el virus luego de alimentarse de un equino infectado, almacenando el virus en su probóscide durante largos periodos de tiempo e inoculando al alimentarse en nuevos equinos susceptibles. Sin embargo, puede ser transmitida de manera mecánica por el uso de agujas o instrumentos quirúrgicos contaminados (21). En Colombia se ha demostrado que la transmisión es más frecuente en áreas con una altitud inferior a 1.500 m.s.n.m.

Según informes de la Oficina Internacional de Epizootias (OIE), en Colombia se reportó la presencia de los HVE-1 y 4 en 1992 (17); sin embargo, no se tiene información más amplia de dicho reporte. Ramírez et al (22), reportaron el primer aislamiento de HVE a partir de tejido de un feto abortado proveniente de un criadero de la Sabana de Bogotá (22), y recientemente, Ruiz et al (23) reportaron la presencia de anticuerpos anti HVE- 4 en mas del $96 \%$ de los equinos evaluados de una muestra de animales pertenecientes a los departamentos de Antioquia y Meta; y anticuerpos contra el HVE- 1 en el $18.8 \%$ y $33.3 \%$ de los animales evaluados en Antioquia y Meta respectivamente (23).

Igualmente, demostraron la presencia del genoma de los HVE-1 y 4 en células mononucleares de sangre periférica de individuos seropositivos y en ganglios trigéminos de equinos de una planta de beneficio del departamento de Antioquia, corroborando de esta forma la presencia del agente viral en el área evaluada (24).

Por otra parte, Ramírez et al (25) refieren que la AlE fue reportada en Colombia en 1948 en el departamento de la Guajira; años más tarde, en 1965 el ICA inició estudios para desarrollar herramientas diagnósticas, $y$ el primer aislamiento del virus y reproducción experimental de la enfermedad en el país, se realizó en esa época (25). En un estudio preliminar realizado por el ICA en 1973, sobre 1000 sueros de equinos, se encontraron mayores niveles de reactores a la prueba de laboratorio en los departamentos de Santander (33\%), Meta (25\%), Cundinamarca (19\%), Valle (13\%) y Antioquia (12\%) (25). Aún cuando la situación epidemiológica ha mejorado, actualmente se reportan muchos estudios seroepidemiológicos en los cuales se presentan prevalencias del $19.72 \%$ en el municipio de Montería, Departamento de Córdoba usando la técnica de c-ELISA (26); y del $1.22 \%$ en la Sabana de Bogotá; $3.52 \%$ en Cartagena D.T.; $3.92 \%$ en Tolima; $7.55 \%$ en Villavicencio y $8.06 \%$ en el departamento del Chocó utilizando la técnica de prueba de inmunodifusión en agar gel de coggins (AGID)(27).

Teniendo en cuenta la amplia cocirculación de los HVE-1 y 4 y el VAIE, y la presencia de enfermedad clínica compatible con la ocasionada por estas entidades en el departamento del Meta, el objetivo del 
trabajo fue determinar el nivel de asociación serológica entre los HVE-1 y 4 causantes de la rinoneumonitis equina y el virus de la anemia infecciosa equina en caballos.

\section{MATERI ALES Y MÉTODOS}

Zonas de muestreo. El muestreo se realizó en 5 municipios del departamento del Meta (San Martín, Guamal, Restrepo, Cumaral y Paratebueno). Se encuentran a una altura de $423 \mathrm{msnm}$, con temperatura promedio de $28^{\circ} \mathrm{C}$, y ubicados en región del Pie de monte del Meta, principalmente utilizando los equinos en sistemas de explotación de tipo extensivo en actividades de vaquería.

Animales y toma de muestras. Mediante un muestreo no probabilístico por conveniencia, se muestreó un total de 68 equinos, los cuales se encontraban clínicamente sanos según la evaluación del médico veterinario. Se tomó dicho número teniendo en cuenta que la población de equinos en esta zona es de aproximadamente 68.618 ejemplares (28); con un nivel de seguridad del $95 \%$, un error del $10 \%$, asumiendo una proporción esperada del $25 \%$ teniendo en cuenta previos estudios del VAIE en el departamento del Meta (25). Se utilizó una fórmula para poblaciones finitas. De los 68 equinos, 9 correspondieron al municipio de San Martín, 10 al de Guamaral, 20 al de Restrepo, 19 al de Cumaral y 10 al de Paratebueno. A cada uno de los animales se les recolectó $10 \mathrm{ml}$ de sangre por punción yugular (Vacutainer ${ }^{\circledR}$ ). La muestra se colectó en un tubo sin anticoagulante (Becton Dickinson VACUTAI NER Systems ${ }^{\circledR}$ ). Posteriormente, las muestras se transportaron refrigeradas al laboratorio, donde se centrifugaron a $4^{\circ} \mathrm{C}$ y a $640 \mathrm{xg}$ para separar el suero, el cual se fraccionó en dos viales que se congelaron a -20 ㅇ $\mathrm{C}$ para su posterior evaluación.

ELISA indirecta. La presencia de anticuerpos específicos de HVE-1 y HVE-4 en las muestras, se determinó utilizando el estuche de diagnóstico SVANOVIR ${ }^{\mathrm{TM}}$ EHVI/ EHV4-Ab ELISA (Svanova Biotech Ab, Suecia). Este estuche permite detectar la presencia de anticuerpos contra la gG de HVE-1 y 4 en muestras de suero equino, utilizando una placa de ELISA de 96 pozos, la cual está sensibilizada con antígenos de HVE-1, antígenos de HVE-4; y además, incluye pozos sensibilizados con un antígeno que se utiliza como control negativo. Si la muestra presenta anticuerpos contra HVE1 o HVE-4, estos forman un complejo antígeno-anticuerpo, el cual es detectado al adicionar el substrato que reacciona con la peroxidasa del anticuerpo conjugado, produciendo finalmente un color amarillo.

En resumen, el procedimiento seguido fue el siguiente: las muestras (suero) se diluyeron 1/100 en solución buffer de dilución; se adicionaron $100 \mu \mathrm{l}$ de cada muestra en los pozos de la placa de ELISA y se incubó por 2 horas a temperatura ambiente; luego se adicionaron $100 \mu \mathrm{l}$ del anticuerpo anti-IgG equina conjugado con la peroxidasa, y de nuevo se incubó durante 1 hora a temperatura ambiente. Se adicionaron posteriormente $100 \mu \mathrm{l}$ de sustrato por pozo y se incubó durante 10 min a temperatura ambiente. Finalmente se adicionaron $50 \mu \mathrm{l}$ de solución de parada que contiene ácido sulfúrico y detiene la reacción. La reacción colorimétrica se torna amarilla cuando el valor es positivo. La lectura se realizó por espectrofotometría a una densidad óptica de $450 \mathrm{~nm}$. Para asegurar la validez del análisis, al valor obtenido de la densidad óptica (DO) para cada muestra, se le restó el valor obtenido para el control (blanco).

Prueba de I nmunodifusión en Agar Gel de Coggins (AGI D). Las pruebas se realizaron en el centro de diagnóstico animal de la regional 8 del ICA en Villavicencio, siguiendo el siguiente procedimiento para las reacciones de inmunodifusión. Se utilizaron cajas de Petri de $100 \mathrm{~mm}$ de diámetro con $15 \mathrm{ml}$ de agar noble al $1 \%$. Con un sacabocados, se realizaron 6 huecos periféricos y uno central sobre el agar los cuales tenían $5 \mathrm{~mm}$ de diámetro y $2.4 \mathrm{~mm}$ de espacio entre ellos. En el centro se colocó el antígeno de AIE control y en tres de los seis pozos externos se colocó un antisuero estándar anti-p26 del VAIE. Las muestras de suero a evaluar se colocaron en los tres pozos restantes. Posteriormente, las cajas de Petri se 
incubaron a temperatura ambiente y en una cámara húmeda durante 72 horas, tiempo para el cual se evaluaron con un haz de luz sobre un fondo oscuro, para evidenciar la presencia de líneas de inmunodifusión entre el suero problema y el antígeno control. Se consideró como "positivo" todo suero que tuviera una reacción similar a la realizada por el antisuero anti-AIE, indicando así la presencia de anticuerpos anti-p26 del VAIE.

Análisis de datos. Para la interpretación de los resultados de ELISA se tomaron como positivas las muestras cuya DO se encontrara por encima de 0.2 luego de sustraer el valor de la DO del respectivo control. Se determinó el porcentaje de seropositividad para HVE-1, HVE-4 y AIE, mediante la relación porcentual entre el número de animales que presentaron anticuerpos positivos y el número de animales evaluados. Adicionalmente se determinó la asociación entre la variable dicotómica presencia de anticuerpos y los HVE-4 y VAIE, mediante el programa de análisis estadístico Prisma $4.0{ }^{\circledR}$ para Windows ${ }^{\circledR}$.

\section{RESULTADOS}

Descripción de la población evaluada. Como se mencionó anteriormente, se tomaron un total de 68 muestras de suero de equinos pertenecientes a 5 municipios del departamento del Meta, las cuales se analizaron mediante una prueba de ELISA indirecto para evaluar la presencia de anticuerpos anti HVE-1 y HVE-4 y mediante la prueba de AGID para evaluar la presencia de anticuerpos anti-VAIE.

Tal como se aprecia en la figura 1 , el $28 \%$ de los equinos muestreados pertenecían al municipio de Cumaral, 29\% al de Restrepo, $15 \%$ al de Guamal, 15\% al de Paratebueno y $13 \%$ al municipio de San Martín. Adicionalmente, la población estaba conformada en $61.8 \%$ por machos y $38.2 \%$ hembras (Figura 2).

Todos los animales se encontraron en las mismas condiciones al momento del muestreo; el rango de edad osciló entre los

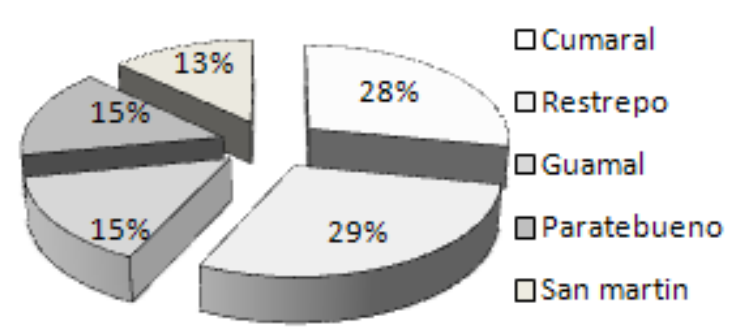

Figura 1. Distribución porcentual de equinos muestreados en cada uno de los municipios evaluados.

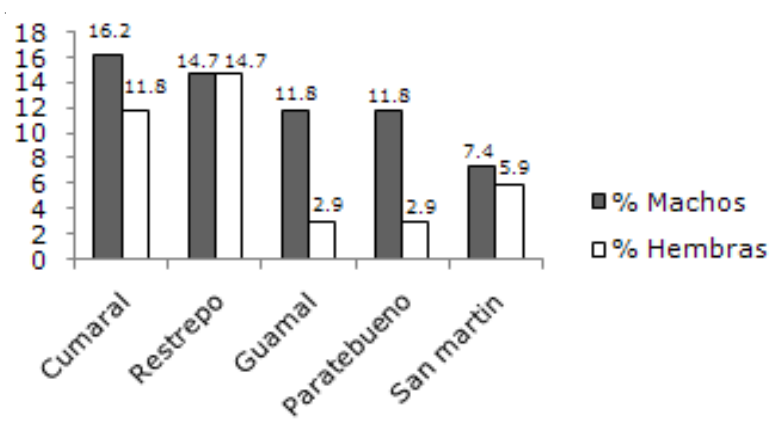

Figura 2. Distribución porcentual de machos y hembras evaluados en cada uno de los municipios muestreados.

3 y 18 años, con una media de 8 años y una moda de 9 años, indicando que la mayoría son animales adultos. Ninguno de los animales muestreados reportaba antecedentes de vacunación contra los herpesvirus equinos.

\section{Seropositividad para el HVE-4 en equinos de 5 municipios del departamento del Meta. El porcentaje acumulado de equinos seropositivos al HVE-4 mediante la prueba de ELISA indirecta fue del 94.12\% (64 positivos de 68 muestreados).}

Cuando se discriminaron los resultados por Municipio se encontró un 27.9\% (19/68) de reactividad en el municipio de Restrepo, 26.5\% (18/68) en Cumaral, 14.7\% (10/68) en Paratebueno, 14.7\% (10/68) en Guamal, y $10.3 \%$ (7/68) en el municipio de San Martin (Figura 3).

Contrario de los resultados anteriormente mencionados para el HVE-4, luego de realizar 


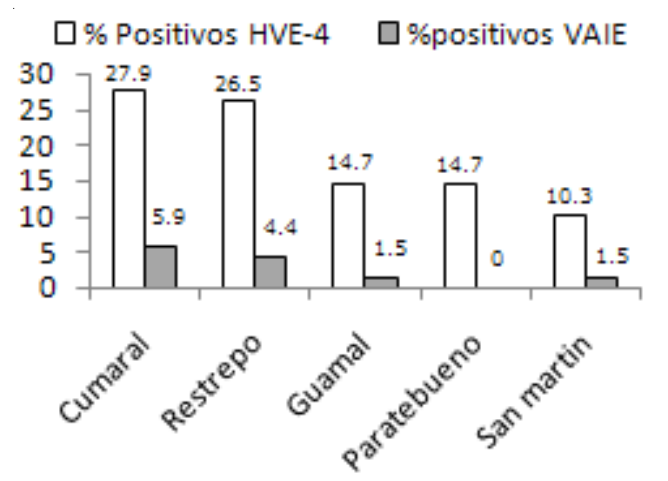

Figura 3. Porcentaje de equinos seropositivos al HVE-4 y al VAIE en 5 municipios del departamento del Meta.

la prueba de ELISA indirecta para determinar la presencia de anticuerpos contra el HVE-1 en los sueros de los equinos de los 5 municipios, ninguno presentó una reacción positiva en la prueba, indicando la ausencia de equinos reactores al HVE-1 en la muestra evaluada.

Respuesta serológica al VAIE en las muestras de suero. Las muestras fueron remitidas al centro de diagnóstico animal de la regional 8 del ICA en Villavicencio, en el cual luego de seguir el procedimiento anteriormente descrito, se encontró que un $13.2 \%$ de la población muestreada (9 positivos de 68 evaluados) presentaron reactividad contra el VAIE indicando su estado infeccioso. Como se puede apreciar en la figura 3, al discernir los hallazgos serológicos por municipios se encontró que el porcentaje de reactores para el municipio de Cumaral fue del $5.88 \%(4 / 68)$, para el de Restrepo de 4.4\% (3/68), para Guamal 1.47\% ( $1 / 68)$ y para el Municipio de San Martin fue del $1.47 \%(1 / 68)$.

Coinfección entre el HVE-4 y el VAI E en la muestra de equinos del Meta. El porcentaje de coinfección en la muestra perteneciente a los 5 municipios fue de $13.32 \%$, ya que todos los individuos que presentaban anticuerpos contra el VAIE se encontraban simultáneamente infectados con el HVE-4. Se encontró además que había significancia estadística en la asociación $(p<0.0001$, OR: 0,01039) presencia de anticuerpos positivos para los HVE-4 y VAIE.

\section{DISCUSIÓN}

Los resultados anteriormente presentados son una mirada al estatus zoosanitario de los equinos de los municipios de Restrepo, Cumaral, Paratebueno, Guamal, y San Martin del departamento del Meta; y realza su importancia el hecho que las infecciones evaluadas son persistentes en los equinos: el HVE-4 causando una infección latente, con periodos de reactivación y excreción de partículas virales (5), y por su parte el VAIE causando una infección lenta permaneciendo el individuo infeccioso durante toda su vida (19).

El alto porcentaje de seropositividad para el HVE-4 en los equinos evaluados (>94\%) está de acuerdo y refuerza los estudios previamente realizados por Ruiz et al en 2006 en una muestra de caballos del departamento del Meta, encontrando un $96.6 \%$ de seropositividad (23). Similares resultados han sido reportados para el Valle de Aburrá/ Oriente cercano de Antioquia, usando la misma prueba serológica, observando que $98.7 \%$ de la población muestreada presentó anticuerpos positivos para HVE-4 (23). En resumen, se puede aseverar que la infección por el HVE-4 en los municipios evaluados se presenta de manera enzoótica, similar a lo reportado para el departamento de Antioquia y como previamente se había dicho para el Meta.

No es raro encontrar una alta prevalencia del VAIE en el departamento del Meta; la literatura reporta seroprevalencias que van del 7 al $25 \%(25,27)$, lo cual sitúa los presentes resultados ( $13.2 \%$ de positivos) en un punto intermedio de infección. Sin embargo, este porcentaje es un resultado altamente preocupante para la explotación zootécnica de equinos y en general para el país; pues demuestra que los sistemas actuales de prevención y control de la infección por el VAIE no han sido efectivos para disminuir la tasa de infección. Si se tiene en cuenta la resolución 1096 del 2005 (29) expedida por el Instituto Colombiano Agropecuario (ICA), lo cual en lo pertinente reza: "Los équidos positivos a la Anemia 
Infecciosa Equina deberán ser identificados con las letras AIE, en el hombro o pierna izquierda para evitar su indebida movilización y comercialización, o acelerar su sacrificio"; sin embargo, a pesar de que los animales muestreados se encuentran positivos, estos difícilmente podrán ser sacrificados debido a los altos costos que implicaría para los propietarios el reemplazo de los animales. Por tanto, siguiendo los lineamientos de dicha resolución se recomendó que estos equinos permanecieran en cuarentena definitiva en el predio de origen hasta su sacrificio y que no fueran ni vendidos, ni comercializados (29).

Poco se ha escrito acerca de la posible interacción del HVE-4 y el VAIE; siempre se han manejado como infecciones independientes, sin embargo, un $13.2 \%$ de coinfección con una asociación estadística positiva es un dato que no se puede descartar, pues se sabe que los caballos infectados por el VAIE presentan fuertes estados de inmunosupresión durante los cuales se facilitaría la reactivación del HVE4 y se dispersaría a nuevos individuos susceptibles. Algunos autores han reportado previamente esta coinfección viral, con resultados contrastantes en los cuales se ha evidenciado in vivo que la infección por el HVE puede afectar la respuesta inmune al VAIE (30). Otros autores demostraron que la presencia de anticuerpos positivos para herpesvirus no modifican la tasa de replicación del VAIE (31). Estos resultados sugieren que existen diferencias en la forma como los equinos regulan las tasas de replicación de las dos infecciones, y que ante la coinfección puede verse afectada la manera como el sistema inmune del hospedero responde a las dos entidades.

Sin embargo, fuera de estas aproximaciones experimentales no hay estudios que reporten la importancia epidemiológica de dicha interacción viral, sobretodo a la hora de establecer programas de prevención y control de estas dos entidades que afectan fuertemente la producción equina del país y del mundo. Por tanto se hace necesario realizar estudios más puntuales de tipo epidemiológico que permitan esclarecer la importancia de la coinfección por estos dos virus y por otros que afecten la salud y la productividad de los equinos.

\section{Agradecimientos}

A los propietarios que permitieron la toma de muestras en sus animales. Este proyecto fue parcialmente financiado por BIOINSTRUMENTAL LTDA (Bogotá D.C) y el Instituto de investigaciones de la Orinoquia Colombiana.

\section{REFERENCI AS}

1 Allen GP. Equine rhinopneumonitis. In: OIE Manual of Diagnostic Tests and Vaccines for Terrestrial Animals, ed. OIE, 5th Edition. París; Office International des Epizooties: 2004.

2 OIE. Equine Infectious Anemia: In: OIE Manual of Diagnostic Tests and Vaccines for Terrestrial Animals, ed. OIE, 5th Edition ed. París; Office International des Epizooties: 2004.

3 Telford EA, Watson MS, Mcbride K, Davison AJ. The DNA sequence of equine herpesvirus-1. Virology 1992; 189: 304316.
4 Telford EA, Watson MS, Perry J, Cullinane $A A$, Davison AJ. The DNA sequence of equine herpesvirus-4. J Gen Virol 1998; 79: 1197-1203.

5 Crabb BS, Studdert MJ. Equine Rhinoneumonitis (equine Herpesvirus 4) and Equine Abortion (equine Herpesvirus 1). In: Virus Infections of Equines, ed. Studdert MJ , ELSEVIER, Holanda 1995.

6 Allen GP. Respiratory Infections by Equine Herpesvirus Types 1 and 4. In: Equine Respiratory Diseases, ed. (Eds) LP. International Veterinary Information Service, Ithaca NY. 2002. 
7 Roizman B, Knipe DM, Whitley RJ. Herpes simplex viruses and their replication. In Fields Virology, Fifth edition. USA; Knipe DM and Howley PM, Editors: 2007.

8 Dimock WW, Edwards PE, Bruner DW. Infections observed in equine fetuses and foals. Cornell Vet Clin North Am Equine Pract 1947; 37: 88-89.

9 Gilkerson JR, Love DN, Whalley JM. Epidemiology of equine herpesvirus abortion: searching clues to the future. Aust Vet J 1998; 76: 675-676.

10 van Maanen $C$, Sloet van OldruitenborghOosterbaan MM, Damen EA, Derksen AG. Neurological disease associated with EHV-1-infection in a riding school: clinical and virological characteristics. Equine Vet J 2001; 33: 191-196.

11 Stierstorfer B, Eichhorn W, Schmahl W, Brandmuller C, Kaaden OR. Equine herpesvirus type 1 (EHV-1) myeloencephalopathy: a case report. J Vet Med B Infect Dis Vet Public Health 2002; 49: 37-41.

12 Gilkerson JR, J orm LR, Love DN, Lawrence GL, Whalley J M. Epidemiological investigation of equid herpesvirus-4 (EHV-4) excretion assessed by nasal swabs taken from thoroughbred foals. Vet Microbiol 1994; 39:275-283.

13 Borchers K, Wolfinger U, Ludwig H. Latency-associated transcripts of equine herpesvirus type 4 in trigeminal ganglia of naturally infected horses. J Gen Virol 1999; 80: 2165-217.

14 Allen GP. Epidemic disease caused by equine herpesvirus-1: recommendations for prevention and control. Equine Vet Educ 2002; 14: 136-142.

15 Lignée $M$. Memoire et observations sur une maladie de sang, connus sous le nom d'anémie hydrohémie. Cachexie aqueuse du cheval. Rec Med Vet Ec Alfort 1843; 20: 30 .
16 Valle H, Carre H. Sur la natur infectieuse de I' anenie du cheval. Acad Sci 1904; 139: 331-333.

17 OIE, HandisTATUS 2004.[fecha de acceso agosto de 2007]. URL disponible en: http://www.oie.int/hs2/report. asp

18 Stein CD, Lotze JC, Mott LO. Transmission of equine infectious anemia by the satablefly, Stomoxys calcitrans, the horse fly, tabanus sulcifrons, and by injection of minute amounts of virus. Am J Vet Res 1942; 4: 183-193.

19 Montelaro RC, Ball J M, Rushlow KE. Equine retroviruses, In Levy JA. (ed), The Retroviridae, vol 2. Plenum Press, New York. 1993.

20 Harrold SM, Cook SJ, Cook FR, Rushlow KE, Issel CJ, Montelaro RC. Tissue Sites of Persistent Infection and Active Replication of Equine Anemia Infectious Virus during Acute Disease and Asymptomatic Infection in Experimentally Infected Equids. J Virol 2000; 74: 3112-3121.

21 Foil LD, Meek CL, Adams WV, Issel CJ, Mechanical transmission of equine infectious anemia virus by deer flies (Chrysops flavidus) and stable flies (Stomoxys calcitrans), Am J Vet Res 1983; 44: 155156.

22 Ramírez GC, Chaparro JJ, Vera VJ, Villamil LC, Romero J R. Primer aislamiento de herpesvirus equino en Colombia. Rev Col Cienc Pec 2001; 14: 73.

23 Ruiz J, Goez YP, Urcuqui-Inchima S, Góngora A, López-Herrera A. Evidencia serológica de la infección por herpesvirus equino tipos 1 y 4 en dos regiones de Colombia. Acta Biol Colomb 2006; 11(2): 186.

24 Ruiz J, Goez Y, Urcuqui-Inchima S, LópezHerrera A. Infección por herpesvirus equino tipos 1 y 4 en células mononucleares de sangre periférica y ganglios trigéminos de equinos. Acta Biol Colomb 2006; 11(2): 187 
25 Ramírez JJ. Hincapié O. Diagnóstico de la Anemia Infecciosa Equina en Colombia por la prueba de inmunodifusión de Coggins. Revista ICA. 1976; 11: 173-179.

26 López J, Mestra O, Reza L. Estudio seroepidemiológico de la anemia infecciosa equina en caballos criollos de paso en las pesebreras del municipio de Montería, Córdoba. Rev.MVZ Córdoba 2000; 5: 20.

27 Sarmiento P, Qijano-Pinzón $M$. Prevalencia del virus de la anemia infecciosa equina ( $A I E$ ) en dos poblaciones de caballos de trabajo de los departamentos del Chocó y la Guajira. Univ Scient 2005; 10: 55-60.
28 Instituto Colombiano Agropecuario - ICACenso poblacional equino 2001. Instituto Colombiano Agropecuario, ICA, 2001.

29 Instituto Colombiano Agropecuario - ICAResolución ICA 1096. Instituto Colombiano Agropecuario, ICA, Abril 4 de 2005

30 Craigo J K, Feng L, Steckbeck JD, Durkin S, Howe L, Cook SJ , et al. Discerning an Effective Balance between Equine Infectious Anemia Virus Attenuation and Vaccine Efficacy. J Virol 2005; 79: 26662677.

31 Smith TA, Davis E, Carpenter S. Endotoxin treatment of equine infectious anaemia virus-infected horse macrophage cultures decreases production of infectious virus. J Gen Virol 1998; 79: 747-755. 